\title{
Investigating Mindfulness, Borderline Personality Traits, and Well-Being in a Nonclinical Population
}

\author{
Mabel Yu*, Mitchell Clark \\ Department of Psychology, Mount Royal University, Calgary, Canada \\ Email: ${ }^{*}$ m.mabelyu@gmail.com
}

Received 29 June 2015; accepted 3 August 2015; published 6 August 2015

Copyright (C) 2015 by authors and Scientific Research Publishing Inc.

This work is licensed under the Creative Commons Attribution International License (CC BY).

http://creativecommons.org/licenses/by/4.0/

(c) (i) Open Access

\begin{abstract}
A growing body of literature has revealed that mindfulness-based interventions consistently have positive outcomes, suggesting that increased mindfulness is related to decreases in psychological symptoms and increases in well-being. In a sample of 110 Mount Royal University undergraduate students, we explored the intercorrelations between mindfulness, borderline personality traits, and subjective well-being (SWB). We hypothesized a negative correlation between mindfulness and borderline personality traits, a positive correlation between mindfulness and SWB, and a negative correlation between borderline personality traits and SWB. To examine, a battery of questionnaire containing four measures was used: Mindful Attention Awareness Scale (MAAS), Five Facet of Mindfulness Questionnaire (FFMQ), Personal Well-being Index (PWI), and Borderline Personality Questionnaire-revised (BPQ). Pearson's correlation and multiple regression analysis results were consistent with our hypotheses. As predicted, higher degrees of mindfulness are associated with less borderline personality traits and greater well-being, whereas the presence of borderline personality traits is linked to lower degrees of well-being. The findings of the present study have significant clinical implications.
\end{abstract}

\section{Keywords}

Mindfulness, Borderline Personality Disorder, Subjective Well-Being

\section{Introduction}

The impressive surge in the popularity of mindfulness has inspired a considerable amount of psychological re-

"Corresponding author. 
search over recent decades, particularly surrounding its clinical relevance. Although mindfulness is derived from Eastern religious teaching, its application in psychology is secular in nature. Mindfulness is often conceptualized in psychology as a mental state characterized by a present-moment awareness and attention to one's private experiences, such as thoughts, feelings, emotions and sensations (Kabat-Zinn, 1994). These experiences are observed and attended to with a nonjudgmental attitude and acceptance (Bishop et al., 2004). The current literature suggests that, even though mindfulness can be understood as a dispositional trait which varies from person to person, individuals can increase their level of mindfulness through mindfulness-based trainings and practices (i.e., meditation) (Baer et al., 2008; Brown \& Ryan, 2003; Falkenström, 2010). The cultivation of mindfulness is of great importance in clinical psychology as researchers and clinicians are beginning to translate the philosophies of mindfulness into practice. A recent shift in the literature has begun investigating its efficacy as a clinical tool against a wide range of psychological symptoms and disorders. Moreover, promising results are demonstrating the effectiveness of mindfulness-based interventions for a number of clinical and nonclinical problems, as well as to improve overall mental and psychological health (e.g., Baer et al., 2008; Grossman, Niemann, Schmidt, \& Walach, 2004).

\subsection{Mindfulness in Clinical Psychology}

The application of mindfulness in psychology was initiated by the introduction of Mindfulness-Based Stress Reduction therapy (MBSR; Kabat-Zinn, 1982), developed for the treatment of chronic pain. Since its establishment, MBSR has also been found successful in reducing the adverse effects of a number of psychological symptoms, including, stress, fatigue and sleep disturbances in cancer patients (Carlson \& Garland, 2005), emotional reactivity in patients with social anxiety disorder (Goldin \& Gross, 2010), and overall psychological stress and anxiety in medical students (Shapiro, Schwartz, \& Bonner, 1998). Additionally, Carmody and Baer (2008) found that MBSR was effective in facilitating emotional well-being in nonclinical samples.

Drawing from MBSR, Teasdale, Segal, \& Williams (1995) developed Mindfulness-Based Cognitive Therapy (MBCT) to prevent relapse in recurring episodes of major depression. Findings suggest that not only is MBCT effective in preventing depressive recurrences (Teasdale et al., 2000), it is also a reliable treatment for a range of additional clinical syndromes, including bipolar disorder (Williams et al., 2008), generalized anxiety disorder (Evans et al., 2008), post-traumatic stress disorder (King et al., 2013), and panic disorder (Kim et al., 2010).

In addition to MBSR and MBCT, other empirically based interventions that reflect mindfulness principles include Acceptance and Commitment Therapy (ACT) (Hayes, Strosahl, \& Wilson, 1999) and Dialectical Behavior Therapy (DBT) (Linehan, 1987). The framework of ACT posits that psychological distress is triggered by attempts to control negative internal experiences, such as maladaptive emotions and thoughts, through private verbal processes (Kang \& Whittingham, 2010). The attempt to exert control over unpleasant events not only increases the frequency and intensity of these experiences, but also exacerbates the negative effects on psychological functioning (Keng, Smoski, \& Robins, 2011).

The integration of mindfulness principles can be seen in DBT, originally developed by Linehan (1987) for the treatment of borderline personality disorder (BPD). DBT has been shown to effectively mitigate maladaptive cognitive patterns and traits in individuals with BPD (Linehan, Armstrong, Suarez, Allmon, \& Heard, 1991). One of the key behavioral skills focused in DBT is the cultivation of mindfulness. Research suggests that the increase in mindfulness skills over the course of treatment is linked to the alleviation of BPD symptoms (Stepp, Epler, Jahng, \& Trull, 2008). Other than treatment for BPD, research has supported the efficacy of DBT for other clinical problems, such as eating disorders, depression, and substance abuse (Dimeff \& Koerner, 2007; Lynch, Morse, Mendelson, \& Robins, 2003; Safer, Telch, \& Agras, 2001).

\subsection{Measuring Mindfulness}

Although mindfulness is an integral part of a number of treatment approaches, its operational definition has not been clearly articulated. However, the definition that is most commonly cited in the literature is provided by Kabat-Zinn (1994): "paying attention in a particular way: on purpose, in the present moment, and nonjudgmentally" (p. 4). It is not until recently that empirical investigations of mindfulness began to appear in the literature. Since the introduction of mindfulness in psychology, researchers have been measuring the construct using selfreport questionnaires. Recently developed measures of mindfulness include the Mindful Attention Awareness 
Scale (MAAS; Brown \& Ryan, 2003), the Kentucky Inventory of Mindfulness Skills (KIMS; Baer, Smith, \& Allen, 2004), the Freiburg Mindfulness Inventory (FMI; Walach, Buchheld, Buttenmüller, Kleinknecht, \& Schmidt, 2006), the Toronto Mindfulness Scale (Lau et al., 2006), and the Five Facet Mindfulness Questionnaire (FFMQ; Baer et al., 2006). Although there exists a number of mindfulness measures, due to the absence of an operational definition, there is an ongoing debate on whether mindfulness should be conceptualized as a unitary or multifaceted construct.

Brown and Ryan (2003) support the single-factor conceptualization in their measure (the MAAS) in which mindfulness is described as the attention to and awareness of present-moment events and experiences. As a unidimensional measure, the MAAS produces a single mindfulness score. Past correlational studies have demonstrated that mindfulness, as measured by the MAAS, is associated with a number of well-being outcomes (Brown \& Ryan, 2003). However, some researchers have argued that assessing complex constructs, such as mindfulness, through a unidimensional measure could risk overlooking the relevant elements that the constructs may encompass (Baer, 2011).

In contrast, the FFMQ developed by Baer et al. (2006) suggests a multifaceted conceptualization of mindfulness. Mindfulness here is defined as the tendency to be mindful of one's internal experiences, such as sensations, emotions, feelings, and thoughts. Through exploratory factor analysis, the researchers integrated preexisting mindfulness questionnaires into a single measure and proposed a five-facet structure of mindfulness. The researchers argued that investigating mindfulness as composed of several facets allows for a clearer understanding of the specific elements that make up the construct and how these elements are related independently to other variables (Baer et al., 2006). Mindfulness, as conceptualized by the FFMQ, is composed of five facets: observing, describing, acting with awareness, nonjudging of inner experience, and nonreactivity to inner experience. The observing facet reflects the ability to notice and attend to one's internal experiences. The describing facet characterizes one's ability to express internal experiences verbally. The acting with awareness facet considers whether one's actions are driven by attention and awareness, as opposed to functioning automatically and thoughtlessly. The nonjudging of inner experience facet reflects one's ability to process internal experiences without evaluating them as positive or negative. Lastly, the nonreactivity to inner experience facet characterizes the tendency to process internal experiences in a non-reactive manner. The FFMQ has demonstrated consistent expected relationships with other measures related to mindfulness (e.g., positive correlations with measures of psychological well-being) (Baer et al., 2008). Furthermore, the validity of conceptualizing mindfulness as a multifaceted construct has been confirmed in later research (Baer et al., 2008).

\subsection{Mindfulness and Borderline Personality Disorder}

Borderline personality disorder (BPD) is one of the most common personality disorders and it is most prevalent amongst young adults (Stone, 1990; Widiger \& Trull, 1993). BPD is characterized by instability in affectivity, self-image, and interpersonal relationships. Individuals suffering from BPD experience frequent mood changes, emotional dysregulation, and increased impulsivity thereby leading to more self-destructive behaviors, such as self-mutilation and suicide (Trull, 1995). Moreover, BPD is highly comorbid with other clinical disorders, including depression, mood and anxiety disorders, eating disorders, and substance abuse (Trull, 1995; Zanarini et al., 1998).

Although BPD is most frequently diagnosed in inpatient and outpatient populations, maladaptive traits of the disorder can also be found in the general (nonclinical) population (Fonseca-Pedrero et al., 2011; Gunderson \& Zanarini, 1987; Trull, 1995). Consistent with the dimensional paradigm of personality disorders which suggests a magnitudinal classification of personality disorders as opposed to a categorical one (Widiger \& Trull, 2007), maladaptive traits of BPD are not considered exclusive to the clinical population. Rather, these traits exist in varying degrees of severity, with clinical-level symptoms resting on the extreme end of the spectrum (Widiger, 1992). Borderline personality traits in the general and subclinical populations would be qualitatively similar to that of the clinical level, although individuals who endorse these traits may not necessarily meet criteria for a full BPD diagnosis (Fonseca-Pedrero et al., 2011; Trull, 1995).

The theoretical framework of BPD recognizes that poor mindfulness skills propagate core features of the disorder. Particularly, symptomatic traits such as pervasive instability in regulating emotions, interpersonal relationships, and behavioral control may be strongly associated with mindfulness deficits (Wupperman, Neumann, \& Axelrod, 2008). Nicastro, Jermann, Bondolfi, \& McQuillan (2010) support this framework, noting that individuals with BPD have poorer mindfulness skills than the community sample. Baer et al. (2004) also found sim- 
ilar results for the discrepancy in mindfulness level between BPD outpatients and a community sample. An explanation of how mindfulness is inversely related to BPD psychopathology is that BPD patient's inability to focus attention to the present moment contributes significantly to their difficulties in self-regulation (e.g., emotional, interpersonal, and behavioral) (Nicastro, Jermann, Bondolfi, \& McQuillan, 2010). Instead, they often engage in avoidance, specifically of situations or events that could trigger unpleasant experiences (e.g., emotions, sensations, thoughts) (Rosenthal, Cheavens, Lejuez, \& Lynch, 2005). While the avoidance of aversive stimuli temporarily reduces distress, the long-term consequences may be the prolongation or exacerbation of symptomatic traits (Hayes, Beevers, Feldman, Laurenceau, \& Perlman, 2005).

While BPD is commonly diagnosed through clinical assessments and interviews, symptomatic traits can also be measured using self-report questionnaires. Some of the most frequently used BPD assessments include, the Borderline Scale of the Personality Assessment Inventory (PAI-BOR; Morey, 1991), the McLean Screening Instrument for Borderline Personality Disorder (MSI-BPD; Zanarini et al., 2003), and the Borderline Personality Scale (STB; Claridge \& Broks, 1984). Adding to the literature, Poreh et al. (2006) recently developed the Borderline Personality Questionnaire (BPQ) as a measure of BPD. The BPQ divides borderline personality traits into nine distinct categories: impulsivity, affective instability, abandonment, relationships, self-image, suicide/self-mutilation, emptiness, intense anger, and quasi-psychotic states. These nine subscales correspond to the nine categories of BPD identified by the DSM-IV (American Psychiatric Association, 1994). Research has confirmed adequate psychometric properties of the BPQ as a measure of borderline personality traits in nonclinical young adults and outpatient youths (Chanen et al., 2008; Fonseca-Pedrero et al., 2011; Poreh et al., 2006).

\subsection{Mindfulness and Subjective Well-Being}

The relationship between mindfulness and well-being is one of the most rigorously researched topics regarding the possible effects of mindfulness. Given the plethora of empirical research concerning this subject, there is a strong indication, as suggested in the literature (e.g., Brown et al., 2007; Brown \& Ryan, 2003; Grossman et al., 2004), that mindfulness is conducive to well-being and supports cognitive and affective indicators of well-being. Such results have been found in diverse samples from both clinical and nonclinical populations.

Investigations into the effects of mindfulness on well-being have been conducted within the context of mindfulness-based treatment interventions, such as MBSR (Kabat-Zinn, 1982) and MBCT (Teasdale, Segal, \& Williams, 1995). The cultivation of mindfulness as a result of interventions has reported to result in a number of positive outcomes related to well-being, including higher levels of positive affect (Brown \& Ryan, 2003; Schutte \& Malouff, 2011), lower levels of negative affect (Brown \& Ryan, 2003; Nyklíček \& Kuijpers, 2008; Shapiro, Brown, \& Biegal, 2007), and greater quality of life (Carlson, Speca, Patel, \& Goodey, 2003; Roth \& Robbins, 2004). Furthermore, increases in mindfulness were associated with decreases in various indicators of poor psychological well-being, such as feelings of distress and depressive symptoms (Shapiro et al., 1998; Speca, Carlson, Goodey, \& Angen, 2000), anxiety (Hofmann, Sawyer, Witt, \& Oh, 2010; Piet, Würtzen, \& Zachariae, 2012), and rumination (Chambers, Lo, \& Allen, 2008; Jain et al., 2007; Shapiro et al., 2007).

Based on existing mindfulness theories and evidence, researchers postulate that mindfulness facilitates well-being directly by encouraging present-moment experience of life events such that these experiences reflect accurate representations of reality. Consequently, mindfulness may reduce the discriminatory cognitive appraisal of situations that could result in psychological disturbances (Brown \& Ryan, 2003). Furthermore, mindfulness may encourage a willingness to experience negative events; thereby reducing perceived stress and fostering adaptive coping to such events (Weinstein, Brown, \& Ryan, 2009).

\subsection{The Present Study}

The purpose of the present study was to examine the intercorrelations among mindfulness, borderline personality traits, and subjective well-being (SWB).

First, the study aimed to explore the correlations between mindfulness and borderline personality traits, and to evaluate the specific associations between individual facets of mindfulness and distinct borderline personality traits. Prior findings have suggested a link between mindfulness deficits and the presence of BPD (Perroud, Nicastro, Jermann, \& Huguelet, 2012; Wupperman, Neumann, \& Axelrod, 2008). Therefore, we predicted a negative correlation between mindfulness and borderline personality traits. Due to the exploratory nature of the present study, no hypotheses were made in terms of the individual associations between mindfulness facets and 
borderline personality traits.

The second, aim was to examine the correlations between mindfulness and SWB, and to determine the strength of association of each mindfulness facet with SWB. Consistent with the previous findings (e.g., Baer et al., 2008; Brown, Ryan, \& Creswell, 2007), we predicted a positive correlation between mindfulness and SWB.

Lastly, the study was intended to explore the correlations between borderline personality traits and SWB, and to assess the associations between individual borderline personality traits and SWB. Consistent with past findings that individuals with BPD have lower self-ratings of emotional well-being (O’Toole, Diddy, \& Kent, 2011), we predicted a negative correlation between borderline personality traits and SWB.

\section{Method}

\subsection{Participants}

The participant pool consisted of 110 undergraduate students (89 females, 21 males) enrolled in introductory psychology courses, age ranging from 18 to 69 years $\left(M_{\text {age }}=21.47\right)$. It is noteworthy that the age of one of the participants (69 years of age) was not reflective of the ages of the other undergraduate students included in the sample. Participants were recruited via a recruitment posting on a psychology research site and were compensated $1 \%$ course credit for their voluntary participation.

\subsection{Materials}

Participants completed a battery of self-report questionnaires and a demographics form that gathered basic demographic characteristics, such as gender, age, and year of study. Also included in the demographics form were questions about their current or previous meditation experience. The questionnaires and the demographics form were administered electronically through an online survey platform.

The battery of questionnaires contained the following measures: MAAS (Brown \& Ryan, 2003), FFMQ (Baer et al., 2006), a revised version of the BPQ (Poreh et al., 2006), and the Personal Well-being Index (PWI; International Wellbeing Group, 2006). The order of presentation of these questionnaires was counterbalanced to control for order effects.

Mindful Attention Awareness Scale (MAAS). The MAAS (Brown \& Ryan, 2003) is a 15-item self-report measure producing a single factor of dispositional mindfulness. The MAAS, which is rated on a 6-point scale (1 = almost never; 6 = almost always), assesses present-moment awareness and attention to events and experiences. The questionnaire includes statements such as: "I find it difficult to stay focused on what's happening in the present" and "I find myself doing things without paying attention". None of the items on the questionnaire require reverse scoring. A sum score is calculated for each participant, with higher scores indicating higher degrees of dispositional mindfulness. The MAAS has shown strong convergent and discriminant validity in past research. In the present study, the MAAS demonstrated good internal consistency with a Cronbach's alpha of 0.88 .

Five Facet Mindfulness Questionnaire (FFMQ). The FFMQ (Baer et al., 2006) is a 39-item self-report measure of mindfulness - as reflected by a tendency to be mindful in daily activities_based on a 5-point scale ranging from 1 (never or very rarely true) to 5 (very often or always true). The five facets represent the five subscales of the questionnaire: observing (8 items; e.g., "when I take a shower or bath, I stay alert to the sensations of water on my body."), describing (8 items; e.g., "I'm good at finding words to describe my feelings.”), acting with awareness (8 items; e.g., "I do jobs or tasks automatically without being aware of what I'm doing."), nonjudging of experience (8 items; e.g., "I criticize myself for having irrational or inappropriate emotions."), and nonreacting of experience (7 items; e.g., "I watch my feelings without getting lost in them."). The sum of the items from a subscale is the total score for that subscale, with higher scores reflecting higher levels of mindfulness. In the present study, the Cronbach's alpha coefficients for the FFMQ indicated adequate to good internal consistency for the subscales (observing, $\alpha=0.75$; describing, $\alpha=0.89$; acting with awareness, $\alpha=0.88$; nonjudging, $\alpha=0.91$; nonreacting, $\alpha=0.77)$, and adequate internal consistency for the overall scale $(\alpha=0.77)$.

Borderline Personality Questionnaire (BPQ). The original BPQ (Poreh et al., 2006) is a self-report questionnaire comprised of 80 dichotomous (true/false) statements. It was developed to assess borderline personality traits based on DSM-IV criteria. The BPQ has a multifactor structure divided into 9 subscales: impulsivity (9 items; e.g., "I often do things without thinking them through."), affective instability (10 items; e.g., "I sometimes feel very happy but this feeling can change quickly."), abandonment (10 items; e.g., "I often become frantic 
when I think that someone I care about will leave me.”), relationships (8 items; e.g., "People often let me down.”), self-image (9 items; e.g., "I feel inferior to other people.”), suicide/self-mutilation (7 items; e.g., "I have threatened to hurt myself in the past.”), emptiness (10 items; e.g., "I often feel empty inside.”), intense anger (10 items; e.g., "I get angry easily.”), and quasi-psychotic states (7 items; e.g., "I sometimes see or hear things that other people cannot see or hear). A point is scored for each "true” statement, with higher scores indicating the presence of more borderline personality traits. A sum score is tallied for each subscale. For the purpose of this study, the BPQ was revised due to ethical concerns.

All of the questions pertaining to the suicide/self-mutilation subscale were removed, leaving a total of 73 questions (8 subscales). This revision was undertaken due to ethical concerns over raising issues of self-harm and causing distress among participants who may have had previous experiences with these issues, The levels of internal consistency for the BPQ subscales used in the study ranged between adequate and good ( $\alpha=0.61$ to $0.87)$, with the exception of the quasi-psychotic states subscale $(\alpha=0.56)$. Nonetheless, the revised BPQ scale demonstrated strong internal consistency overall with a Cronbach's alpha of 0.92 .

Personal Well-Being Index (PWI). The PWI (5 ${ }^{\text {th }}$ edition; International Wellbeing Group, 2006) is a self-report measure of SWB rated on an 11-point scale $(0=$ completely dissatisfied; $10=$ completely satisfied $)$. SWB typically reflects the degree of satisfaction with regards to how an individual perceives themselves in a number of life domains (International Wellbeing Group, 2006). It is synonymous with life satisfaction or quality of life. The PWI is an 8-item questionnaire, with an additional (optional) item used to test the construct validity of the measure. The eight items correspond to a quality of life domain-standard of living, health, achieving in life, relationships, safety, community-connectedness, future security, and spirituality/religion. The additional item assesses general life satisfaction. The responses from the eight items are summed to yield an overall SWB score. Due to an entry error, the health domain was excluded from the study, leaving a total of seven items. However, we do not anticipate any significant impact to the results as a consequence of this error. In the present study, the PWI demonstrated good internal consistency with a Cronbach’s alpha of 0.84.

\subsection{Procedure}

The study was conducted in a group setting in the university's psychology laboratory. As soon as participants entered the study area, they were seated in front of a computer. After informed consent was obtained, participants were directed to the website containing the questionnaire packet and the demographics form. Upon the completion of the demographics form, each participant received a debriefing form and was asked by the researcher if they had any questions or concerns regarding the study. Finally, participants were thanked for their time and participation in the study. On average, participants completed the study within 30 minutes.

\section{Results}

All of the data were analyzed using SPSS 22.0. It is important to note that the problem of missing data was treated using mean substitution. Although there are alternative procedures, because the number of missing data in the dataset was not substantial and we suspect that the pattern of missing data is completely at random (MCAR), the process of mean substitution should not have a significantly effect on the overall results (Kline, 1998; Tabachnick \& Fidell, 2001).

All of the data were screened to test several key assumptions: skewness and kurtosis for normality, multicollinearity, and homoscedasticity. The data appeared to satisfy the aforementioned assumptions. Outliers were also screened and a few were detected, however, no extreme outliers were found and the removal of the outliers did not change the results significantly for each but one analysis. Therefore, outliers that did not affect the results were retained in the dataset for further analysis; whereas, the outliers that had a significant effect on the results were removed. The results pertaining to the influence of outliers will be further discussed in a later section.

Pearson's correlation coefficients between the total score of all of the scales were calculated. FFMQ, MAAS and PWI were all significantly inversely correlated with BPQ, FFMQ was significantly positively correlated with MAAS, and FFMQ and MAAS both were significantly positively correlated with PWI. Correlation coefficients, means and standard deviations of all of the study variables are presented in Table 1.

\subsection{Mindfulness and Borderline Personality Traits}

Pearson's correlation coefficients were calculated to determine the relationship between the five FFMQ facets 
Table 1. Means, standard deviations and intercorrelations among sum scores of all measures.

\begin{tabular}{ccccccc}
\hline Measures & 1 & 2 & 3 & 4 & Mean & SD \\
\hline 1. FFMQ & - & & & 122.03 & 18.01 \\
2. MAAS & $0.64^{* *}$ & - & & 56.48 & 12.28 \\
3. BPQ & $-0.66^{* *}$ & $-0.48^{* *}$ & - & & 22.45 & 12.12 \\
4. PWI & $0.46^{* *}$ & $0.28^{*}$ & $-0.59^{* *}$ & - & 7.22 & 1.48 \\
\hline
\end{tabular}

Note: $\mathrm{FFMQ}=$ Five Facet Mindfulness Questionnaire; MAAS = Mindful Attention Awareness Scale; $\mathrm{BPQ}=$ Borderline Personality Questionnaire; PWI = Personal Well-Being Index. ${ }^{*} p<0.01 ;{ }^{* * *} p<0.001$.

and the eight BPQ subscales (see Table 2). Most of the facets had significant negative correlations with BPQ subscales or trended toward statistical significance. However, Pearson's correlation of the FFMQ observing facet and the BPQ quasi-psychotic states subscale (BPQ) demonstrated results dissimilar from the general trend.

The observing facet was not significantly correlated with most of the BPQ subscales other than relationship and quasi-psychotic states; however, the latter correlation was positive. Moreover, the correlation between the observing facet and the impulsivity subscale also trended towards a positive direction.

As for the BPQ quasi-psychotic states subscale, although it showed a significant negative correlation with the FFMQ nonjudging facet, the majority of the correlations trended toward a positive direction. Specifically, quasi-psychotic states demonstrated positive correlations with the FFMQ facets observing, describing, and nonreacting, although showing significance only with observing.

A multiple regression analysis was performed to identify the FFMQ facet that best predicted total BPQ. It is important to note here that outliers were removed during the analysis which saw a significant change to the describing facet. With the inclusion of outliers, describing did not significantly predict total BPQ $(\beta=-0.13, p=$ 0.11). After the removal of outliers, however, describing did significantly and independently predict total BPQ $(\beta=-0.18, p=0.02)$. Overall, the five FFMQ facets significantly predicted total BPQ showing that the five facets accounted for approximately $56 \%$ of the variance. All of the facets except for observing significantly contributed to the regression equation. Nonjudging was the strongest predictor of total BPQ score, followed by acting with awareness. The results are shown in Table 3.

Next, a number of multiple regression analyses were performed to determine which mindfulness facet was most strongly related to each individual borderline personality subscale. The five FFMQ facets significantly predicted all of the individual BPQ subscales. The observing facet significantly predicted quasi-psychotic states (though trended positively), the describing facet significantly predicted abandonment, the acting with awareness facet significantly predicted impulsivity, the nonjudging facet significantly predicted affective instability, abandonment, relationships, self-image, emptiness, intense anger, and quasi-psychotic states, and the nonreacting facet significantly predicted affective instability and intense anger. The results are presented in Table 3.

\subsection{Mindfulness and Subjective Well-Being}

Pearson's correlation coefficients were calculated to examine the relationship between the five FFMQ mindfulness facets and PWI. As presented in Table 2, all five FFMQ facets correlated significantly and positively with the PWI.

Next, a multiple regression analysis was performed to identify the mindfulness facet that best predicted PWI. To determine this, the PWI was regressed onto the five FFMQ facets. The five FFMQ facets significantly predicted PWI, showing that the five facets together significantly explained $18 \%$ of the variance. Individually, only the nonjudging facet significantly predicted PWI. The results are shown in Table 4.

\subsection{Borderline Personality Traits and Subjective Well-Being}

Pearson's correlation coefficients were calculated to determine the associations between the eight BPQ subscales and PWI. As shown in Table 2, all BPQ subscales had significant negative correlations with PWI, with the exception of the quasi-psychotic states subscale.

A multiple regression analysis was conducted to determine which BPQ subscale best predicted PWI. To examine, the PWI was regressed onto the eight BPQ subscales. The BPQ subscales significantly predicted PWI, 
Table 2. Means, standard deviations and intercorrelations of mindfulness facets, borderline personality traits subscales, and subjective well-being.

\begin{tabular}{|c|c|c|c|c|c|c|c|c|c|c|c|c|c|c|c|c|}
\hline Variables & 1 & 2 & 3 & 4 & 5 & 6 & 7 & 8 & 9 & 10 & 11 & 12 & 13 & 14 & Mean & SD \\
\hline $\begin{array}{l}\text { 1. FFMQ } \\
\text { OBS }\end{array}$ & - & & & & & & & & & & & & & & 26.44 & 4.91 \\
\hline $\begin{array}{l}\text { 2. FFMQ } \\
\text { DES }\end{array}$ & $0.29^{* *}$ & - & & & & & & & & & & & & & 26.32 & 5.99 \\
\hline $\begin{array}{l}\text { 3. FFMQ } \\
\text { AA }\end{array}$ & 0.15 & $0.39^{* * *}$ & - & & & & & & & & & & & & 24.25 & 5.37 \\
\hline $\begin{array}{l}\text { 4. FFMQ } \\
\text { NJ }\end{array}$ & 0.08 & $0.33^{* * *}$ & $0.47^{* * *}$ & - & & & & & & & & & & & 24.39 & 6.51 \\
\hline $\begin{array}{l}\text { 5. FFMQ } \\
\text { NR }\end{array}$ & $0.38^{* * *}$ & 0.16 & $0.40^{* * *}$ & $0.39^{* * *}$ & - & & & & & & & & & & 20.63 & 4.17 \\
\hline $\begin{array}{l}\text { 6. BPQ } \\
\text { IMP }\end{array}$ & 0.07 & -0.11 & $-0.38^{* * * *}$ & -0.17 & -0.004 & - & & & & & & & & & 2.32 & 1.83 \\
\hline $\begin{array}{l}\text { 7. BPQ } \\
\text { AI }\end{array}$ & -0.13 & $-0.27^{* *}$ & $-0.44^{* * *}$ & $-0.48^{* * * *}$ & $-0.40^{* * *}$ & 0.17 & - & & & & & & & & 5.02 & 3.28 \\
\hline $\begin{array}{l}\text { 8. BPQ } \\
\text { ABDN }\end{array}$ & -0.10 & $-0.38^{* * *}$ & $-0.42^{* * *}$ & $-0.51^{* * *}$ & $-0.32^{* *}$ & $0.20^{*}$ & $0.47^{* * *}$ & - & & & & & & & 2.15 & 1.79 \\
\hline $\begin{array}{l}\text { 9. BPQ } \\
\text { REL }\end{array}$ & $-0.22^{*}$ & $-0.31^{* *}$ & $-0.37^{* * *}$ & $-0.38^{* * *}$ & $-0.32^{* *}$ & $0.21^{*}$ & $0.40^{* * *}$ & $0.56^{* * *}$ & - & & & & & & 2.94 & 2.34 \\
\hline $\begin{array}{l}\text { 10. BPQ } \\
\text { SI }\end{array}$ & -0.07 & $-0.27^{* *}$ & $-0.36^{* * * *}$ & $-0.53^{* * *}$ & $-0.30^{* *}$ & 0.15 & $0.36^{* * *}$ & $0.50^{* * *}$ & $0.40^{* * *}$ & - & & & & & 2.50 & 2.38 \\
\hline $\begin{array}{l}\text { 11. BPQ } \\
\text { EMPT }\end{array}$ & -0.07 & $-0.30^{* *}$ & $-0.39^{* * *}$ & $-0.48^{* * * *}$ & $-0.29^{*}$ & 0.10 & $0.44^{* * *}$ & $0.53^{* * *}$ & $0.42^{* * *}$ & $0.66^{* * *}$ & - & & & & 3.11 & 2.62 \\
\hline $\begin{array}{l}\text { 12. BPQ } \\
\text { ANGR }\end{array}$ & -0.04 & $-0.20^{*}$ & $-0.40^{* * * *}$ & $-0.46^{* * * *}$ & $-0.48^{* * * *}$ & 0.13 & $0.59^{* * *}$ & $0.35^{* * *}$ & $0.34^{* * *}$ & $0.34^{* * *}$ & $0.39^{* * * *}$ & - & & & 2.68 & 2.78 \\
\hline $\begin{array}{c}\text { 13. BPQ } \\
\text { QPS }\end{array}$ & $0.24^{*}$ & 0.02 & -0.14 & $-0.22^{*}$ & 0.02 & 0.19 & 0.16 & 0.05 & 0.06 & 0.11 & $0.20^{*}$ & 0.17 & - & & 1.73 & 1.52 \\
\hline 14. PWI & $0.21^{*}$ & $0.34^{* * *}$ & $0.34^{* * * *}$ & $0.36^{* * *}$ & $0.25^{* *}$ & $-0.26^{* *}$ & $-0.33^{* * *}$ & $-0.54^{* * * *}$ & $-0.44^{* * *}$ & $-0.52^{* * *}$ & $-0.56^{* * *}$ & $-0.32^{* * * *}$ & -0.04 & - & 50.57 & 10.37 \\
\hline
\end{tabular}

Note: FFMQ = Five Facet Mindfulness Questionnaire; OBS = Observing; Des = Describing; AA = Acting with Awareness; NJ = Nonjudging; NR = Nonreacting; BPQ = Borderline Personality Questionnaire; IMP = Impulsivity; AI = Affective Instability; ABDN = Abandonment; REL = Relationships; SI = Self-Image; EMPT = Emptiness; ANGR = Intense Anger; QPS = Quasi-Psychotic States; PWI = Personal Well-Being Index. ${ }^{*} p<0.05$, ${ }^{* *} p$ $<0.01, \stackrel{* * *}{p}<0.001$.

showing that the BPQ subscales together significantly explained $41 \%$ of the variance. Individually, the subscales impulsivity, abandonment, and emptiness significantly predicted PWI, with impulsivity as the best predictor of PWI. The results are shown in Table 5.

\section{Discussion}

The present study sheds light on the associations among mindfulness, borderline personality traits, and subjective well-being. The findings support the hypotheses that mindfulness and subjective well-being are correlated negatively with borderline personality traits, and that mindfulness is positively correlated with subjective well-being.

\subsection{Relations between Mindfulness and Borderline Personality Traits}

As predicted, mindfulness demonstrated an inverse relationship with borderline personality traits. Interestingly, Pearson's correlation between BPQ and FFMQ scores reflects a stronger relationship than the correlation between BPQ and MAAS scores. A possible explanation could be that, as opposed to the MAAS which conceptualizes mindfulness as a unitary construct, the multifaceted structure of the FFMQ covers mindfulness dimensions that are pertinent to BPD features. Although the differences in the results between the FFMQ and the MAAS are small, the findings may be taken to support the conceptualization of mindfulness as a multidimensional construct, as is favored by recent mindfulness research (e.g., Baer et al., 2006). 
Table 3. Summaries of multiple regression analysis predicting total borderline personality traits and borderline personality subscales from mindfulness facets.

\begin{tabular}{|c|c|c|c|c|}
\hline Dependent Variable & Predictors & $R^{2}$ & adj. $R^{2}$ & $\beta$ \\
\hline \multirow[t]{5}{*}{ Total BPQ } & Observing & $0.58^{* * *}$ & $0.56^{* * *}$ & $0.09^{\mathrm{a}}$ \\
\hline & Describing & & & $-0.18^{\mathrm{a}^{*}}$ \\
\hline & Acting with awareness & & & $-0.27^{7^{* *}}$ \\
\hline & Nonjudging & & & $-0.42^{\mathrm{a}^{* * *}}$ \\
\hline & Nonreacting & & & $-0.17^{\mathrm{a}^{*}}$ \\
\hline \multirow[t]{5}{*}{ Impulsivity } & Observing & $0.18^{* * *}$ & $0.14^{* *}$ & 0.70 \\
\hline & Describing & & & 0.27 \\
\hline & Acting with awareness & & & $-0.45^{* * *}$ \\
\hline & Nonjudging & & & -0.04 \\
\hline & Nonreacting & & & 0.16 \\
\hline \multirow[t]{5}{*}{ Affective instability } & Observing & $0.32^{* * *}$ & $0.29^{* * *}$ & 0.02 \\
\hline & Describing & & & -0.08 \\
\hline & Acting with awareness & & & $-0.19^{\mathrm{b}}$ \\
\hline & Nonjudging & & & $-0.28^{* *}$ \\
\hline & Nonreacting & & & $-0.21^{*}$ \\
\hline \multirow[t]{5}{*}{ Abandonment } & Observing & $0.35^{* * *}$ & $0.32^{* * *}$ & 0.05 \\
\hline & Describing & & & $-0.21^{*}$ \\
\hline & Acting with awareness & & & -0.15 \\
\hline & Nonjudging & & & $-0.33^{* *}$ \\
\hline & Nonreacting & & & -0.12 \\
\hline \multirow[t]{5}{*}{ Relationships } & Observing & $0.24^{* * *}$ & $0.20^{* * * *}$ & -0.10 \\
\hline & Describing & & & -0.14 \\
\hline & Acting with awareness & & & -0.16 \\
\hline & Nonjudging & & & $-0.20^{*}$ \\
\hline & Nonreacting & & & -0.12 \\
\hline \multirow[t]{5}{*}{ Self-image } & Observing & $0.32^{* * *}$ & $0.28^{* * *}$ & 0.04 \\
\hline & Describing & & & -0.09 \\
\hline & Acting with awareness & & & -0.09 \\
\hline & Nonjudging & & & $-0.44^{* * *}$ \\
\hline & Nonreacting & & & -0.10 \\
\hline \multirow[t]{5}{*}{ Emptiness } & Observing & $0.28^{* * *}$ & $0.25^{* * *}$ & 0.06 \\
\hline & Describing & & & -0.13 \\
\hline & Acting with awareness & & & -0.15 \\
\hline & Nonjudging & & & $-0.33^{* *}$ \\
\hline & Nonreacting & & & -0.10 \\
\hline \multirow[t]{5}{*}{ Intense anger } & Observing & $0.35^{* * *}$ & $0.32^{* * *}$ & 0.16 \\
\hline & Describing & & & -0.05 \\
\hline & Acting with awareness & & & -0.14 \\
\hline & Nonjudging & & & $-0.24^{*}$ \\
\hline & Nonreacting & & & $-0.38^{* * *}$ \\
\hline \multirow[t]{5}{*}{ Quasi-psychotic states } & Observing & $0.12^{*}$ & $0.08^{*}$ & $0.24^{*}$ \\
\hline & Describing & & & 0.05 \\
\hline & Acting with awareness & & & -0.11 \\
\hline & Nonjudging & & & $-0.23^{*}$ \\
\hline & Nonreacting & & & 0.05 \\
\hline
\end{tabular}

Note: $\mathrm{BPQ}=$ Borderline Personality Questionnaire; FFMQ = Five Facet Mindfulness Questionnaire. ${ }^{\mathrm{a}}$ Outlier removed in analysis; ${ }^{\mathrm{b}}$ Marginally significant at $p<0.05 .{ }^{*} p<0.05 ;{ }^{* *} p<0.01 ;{ }^{* * *} p<0.001$. 
Table 4. Summary of multiple regression analysis predicting subjective well-being from mindfulness facets.

\begin{tabular}{cccc}
\hline Dependent Variable & Predictors (FFMQ) & $R^{2}$ & adj. $R^{2}$ \\
\hline Subjective well-being (PWI) & Observing & $0.22^{* *}$ & $0.18^{* *}$ \\
& Describing & 0.11 & 0.18 \\
& Acting with awareness & 0.14 \\
$0.22^{*}$ & 0.05 \\
\hline
\end{tabular}

Note: PWI = Personal Well-Being Index; FFMQ = Five Facet Mindfulness Questionnaire. ${ }^{*} p<0.05 ;{ }^{* *} p<0.001$.

Table 5. Summary of multiple regression analysis predicting subjective well-being from borderline personality traits.

\begin{tabular}{|c|c|c|c|c|}
\hline Dependent Variable & Predictors (BPQ) & $R^{2}$ & $\operatorname{adj} . R^{2}$ & $\beta$ \\
\hline \multirow[t]{8}{*}{ Subjective well-being (PWI) } & Impulsivity & $0.56^{* *}$ & $0.41^{* * * *}$ & $-0.16^{*}$ \\
\hline & Affective instability & & & 0.06 \\
\hline & Abandonment & & & $-0.22^{*}$ \\
\hline & Relationships & & & -0.10 \\
\hline & Self-Image & & & -0.16 \\
\hline & Emptiness & & & $-0.30^{* *}$ \\
\hline & Intense anger & & & -0.06 \\
\hline & Quasi-psychotic states & & & 0.09 \\
\hline
\end{tabular}

Note: PWI = Personal Well-Being Index; BPQ = Borderline Personality Questionnaire. ${ }^{*} p<0.05 ;{ }^{* *} p<0.01 ;{ }^{* * *} p<0.001$.

The finding that mindfulness and borderline personality traits are inversely related is consistent with previous research (e.g., Baer, Smith, \& Allen, 2004; Wupperman, Neumann, \& Axelrod, 2008). As BPD is characterized by deficits in mindfulness, increasing these skills may mitigate the expression of borderline personality traits. For example, mindfulness can help reduce difficulties with emotional dysregulation, a key characteristic of BPD, by teaching individuals to realize that aversive emotions and thoughts are transient events that do not require an immediate response. This notion is consistent with past research that suggests mindfulness promotes better emotional differentiation. This improvement is linked to the reduction of emotional difficulties such as emotional lability (otherwise known as emotional instability) and dysregulation (Hill \& Updegraff, 2012; Koenigsberg et al., 2002). Moreover, Brown and Ryan (2003) found that being mindful is associated with better emotional regulation in the general population. Through the practice of mindfulness, particularly by realizing that private experiences are merely self-construed expressions of temporary events rather than accurate reflections of reality, individuals with BPD or features of BPD will be able effectively regulate their behaviors and emotions in order to reduce distress and alleviate maladaptive symptoms. Further, the tendency to be mindful may promote effective coping strategies in the face of negative or distressing events.

In the present study, we also found that mindfulness facets relate differentially to BPD symptoms. In other words, each mindfulness facet operates uniquely in the expression of borderline personality traits. This is consistent with past findings which demonstrate that mindfulness facets have unique relationships with various psychological symptomatology (Barnhofer, Duggan, \& Griffith, 2011; Nicastro et al., 2010; Peters, EisenlohrMoul, \& Baer, 2013).

We found that the nonjudging facet had the strongest relationship with the total borderline personality traits score, as well as with most borderline personality trait subscales. This is consistent with Cash and Whittingham (2010) who found that nonjudging had predicted lower levels of stress, anxiety, and depression-related symptomatology. Furthermore, Baer et al. (2006) also found that of all five facets of mindfulness, nonjudging had the highest correlations with psychological symptoms, neuroticism, thought suppression, emotion dysregulation, and experiential avoidance. These findings suggest that having an attitude of acceptance and nonjudgment is critical in mitigating BPD and its core features. This is related to past research which showed that individuals 
with BPD have difficulties paying attention to, and be accepting of their emotions, thoughts, and sensations (Hayes et al., 1996; Rosenthal, Cheavens, Lejuez, \& Lynch, 2005). Moreover, they engage in habitual avoidance/escape responses to control their private experience as well as situations that elicit awareness to these experiences (Bijttebier \& Vertommen, 1999; Kruedelbach, McCormick, Schulz, \& Grueneich, 1993). Avoidance of stressors usually results in the temporary reduction of unpleasant experiences, thus reinforcing the avoidance behavior. However, the long-term consequences include the worsening of negative affect, which may exacerbate BPD symptoms (Hayes, Beevers, Feldman, Laurenceau, \& Perlman, 2005). Since avoidance also precludes one from engaging in effective means to regulate stressors, these stressors will continue to be evaluated as "bad", thereby prolonging and potentially intensifying these aversive experiences. From this perspective, it is imperative and highly beneficial to assume a nonjudgmental stance of one's private experience, for example, accepting these experiences as they are rather than evaluating them as "good" or "bad". Taken together, the present findings suggest that learning to not judge one's private experience may be crucial in the improvement of BPD and its traits.

Looking at other individual associations of mindfulness facets with borderline personality traits, we also found that the acting with awareness mindfulness facet was the strongest predictor of impulsivity. This is consistent with findings by Peters, Erisman, Upton, Baer, \& Roemer (2011) which showed that all five FFMQ facets were significantly correlated with impulsivity as measured using the Barratt Impulsiveness Scale-11 (BIS-11; Patton et al., 1994), with the acting with awareness facet having the strongest zero-order correlation. These findings are supportive of past research indicating that individuals with BPD engage in impulsive and self-destructive behaviors in response to distressing emotions (Bornovalova, Lejuez, Daughters, Rosenthal, \& Lynch, 2005; Gratz, Breetz, \& Tull, 2010; Peters, Upton, \& Baer, 2013). The strong association between impulsivity and acting with awareness suggests that having an increased awareness of your actions, as cultivated through mindfulness, could facilitate adaptive behavioral regulation, thereby reducing the tendencies for individuals with BPD or its traits to engage in impulsive behavior.

Additionally, we also found that the acting with awareness facet was the second highest predictor of total borderline personality traits, and had the second highest correlation with most of the borderline personality subscales. These findings are similar with Baer et al. (2006) who found that the acting with awareness facet had the second strongest relationship with psychological symptoms, neuroticism, thought suppression, and emotional dysregulation. Furthermore, the results are consistent with prior findings indicating that individuals who express borderline personality features tend to be deficient in emotional awareness such that they have difficulties paying attention to and being aware of their emotional experiences (Leible \& Snell, 2004). Consistent with this perspective, the mindfulness principle of increasing awareness should allow individuals to draw distinctions between specific emotional states, which should inherently promote effective emotional regulation. It is crucial, therefore, to encourage greater emotional awareness to reduce the expression of borderline personality traits.

A majority of the correlations in the study were consistent with our predictions, however, the findings for the observing mindfulness facet revealed a markedly differing trend in predicting borderline personality traits. Interestingly, these results are in concordance with previous research. Baer et al. (2004) were the first to discuss the significance of this finding in their study, which examined mindfulness in meditating and non-meditating samples. The authors suggested that in populations without meditation experience, engaging in the observation of private experience may provoke reactions inconsistent with, or even counter to the outcomes associated with the practice of mindfulness. Further, Baer et al. (2006) postulated that observing may elicit self-focused attention in non-meditating samples that is ruminative and therefore maladaptive. The findings from our study regarding the observing facet of mindfulness provide further evidence that the observation of private experience is only beneficial insofar as it is processed mindfully.

Similar to the observing mindfulness facet, the quasi-psychotic states BPQ subscale also revealed unexpected results. The pattern of results for the quasi-psychotic states BPQ subscale could be due to the reduced presence of this trait in our sample, as this particular trait can be expected with greater frequency and severity within a clinical population. However, we anticipate that the correlations between the quasi-psychotic states subscale and the mindfulness facets would parallel the normative trend that was found in our study in samples where symptoms indicative of this subscale are more prominent.

Taken together, the findings suggest that nonjudging and acting with awareness are the two most important mindfulness facets in predicting borderline personality traits, whereas observing one's private experience may result in consequences inconsistent with mindfulness principles in individuals with minimal or no meditation 
experience.

\subsection{Relations between Mindfulness and Subjective Well-Being}

The present study also examined the relationship between mindfulness and SWB. As predicted, we found a positive correlation between mindfulness and SWB, suggesting that individuals who have higher levels of mindfulness will perceive their quality of life to be greater. Similar to the results between mindfulness and borderline personality traits, Pearson's correlation between the PWI and FFMQ scores reveals a stronger association than the correlation between PWI and MAAS scores. Once again, the findings lend support to the notion that mindfulness should be conceptualized as a multifaceted construct as opposed to a unidimensional construct.

Our findings are consistent with the literature which provides overwhelming evidence indicating that mindfulness is associated with an enhanced sense of well-being (e.g., Brown \& Ryan, 2003; Carmody \& Baer, 2008). Researchers have suggested that mindfulness, particularly the mechanism of paying attention to the present moment and enhancing self-regulation, may facilitate greater well-being (Brown, Ryan, \& Creswell, 2007). Furthermore, mindfulness also contributes to well-being through the enhancement of behavioral regulation as a result of heightened attention to experiences (Brown \& Ryan, 2003). Since mindful individuals are likely to view unpleasant experiences as temporary and are more accepting of these experiences, we postulate that these events will not have a damaging effect on their well-being. Furthermore, because mindfulness also encourages individuals to become aware of the stream of thoughts and feelings in the present moment, this aspect of mindfulness should, as a result, facilitate greater well-being as individuals learn to regulate their experiences appropriately and effectively.

Looking at the individual correlations of mindfulness facets with SWB, we found that all five facets positively correlated with SWB. Moreover, we found that only the nonjudging facet significantly and independently predicted SWB. These findings are similar to Baer et al. (2008) who found that all facets except observing significantly and independently predicted well-being. However, these findings are inconsistent with results by Cash and Whittingham (2010) in which none of the FFMQ mindfulness facets significantly predicted well-being. This is particularly interesting because the same well-being measure-the PWI-was used in both the present study and the one by Cash and Whittingham (2010). Whereas Baer et al. (2008) assessed well-being using the Psychological Well-Being Measure (PWB). Thus, further research using the PWI is necessary to understand the link between mindfulness and well-being.

\subsection{Relations between Borderline Personality Traits and Well-Being}

The present study also examined the relationship between borderline personality traits and subjective well-being. As predicted, we found a significant negative correlation between borderline personality traits and subjective well-being. Moreover, we also found that all of the borderline personality traits with the exception of quasi-psychotic states have significant negative associations with subjective well-being. These findings are concordant with previous research which found that female BPD patients reported lower quality of life than healthy female individuals (Rüsch et al., 2007). Furthermore, we also found that impulsivity, abandonment, and emptiness independently and significantly predicted subjective well-being. These findings suggest the importance of reducing the symptoms related to impulsivity, feelings of abandonment and emptiness to facilitate improvements in one's perception of their overall life satisfaction.

Individuals with BPD or its traits are often overcome by maladaptive thoughts and feelings, which prevents them from acknowledging and experiencing positive events that may occur. Since these individuals have problems regulating their emotions and behaviors, they are more likely to engage in maladaptive thinking and actions that could have a detrimental effect on their well-being. In sum, the present findings suggest that BPD has a substantial impact on one's quality of life, even in subclinical populations wherein individuals may only express a minimal degree of the disorder, and not enough for a full clinical diagnosis.

\subsection{Limitations, Implications, and Future Directions}

Although this is the first study to our knowledge to examine the relationship between the five mindfulness facets using the FFMQ with BPD subscales from the BPQ, due to the correlational nature of the study, the findings should be interpreted with caution, as correlations do not signify causation. Further, it should be highlighted that the directions of the correlations concluded from the present study could be explained in the opposite way. For 
example, although we concluded that mindfulness is linked to improved well-being, the reverse could be proposed. That is, it can be argued that higher levels of subjective well-being are associated with mindfulness perhaps because individuals with greater well-being have access to adaptive resources (i.e., better emotional regulation) that in turn could increase their mindfulness level. A suggestion for future research would be to use experimental methods to determine the causal relationship of the study variables.

Other possible limitations of the study include the use of self-report measures and a student sample. Although previous studies have validated the psychometric properties of the measures that were used in the present study, self-report measures are still susceptible to reporting bias. This limitation is especially relevant to our study since individuals with BPD, or those who endorse BPD traits, may falsify their responses to conceal their symptoms, which would undermine the accuracy of the results. To overcome this limitation, future research could implement a response check such as the Marlowe-Crown Social Desirability scale (Reynolds, 1982) to assess for social desirability bias. Another way to compensate for the vulnerability in self-report is to use behavioral measures. However, due to the fact that mindfulness is a complicated and abstract construct, a majority of empirical research on mindfulness currently in the literature is correlational. Therefore, future research should focus on examining the effects of mindfulness on relevant variables using behavioral measures.

In regard to the potential limitation of a student sample, while the measures that were used in the study have demonstrated good psychometric properties in these types of samples, however, the present findings may not be generalizable to other populations. Thus, future research should replicate the present study outside a student population. Furthermore, generalizing the findings to individuals with a BPD diagnosis is limited, as the sample was composed of a nonclinical population. Therefore, replications of these findings are warranted in clinical populations. It would be valuable to examine the relationship between specific facets of mindfulness and the different features of BPD in the clinical population in order to advance more effective strategies in the treatment of the disorder. For example, since we found that nonjudging and acting with awareness have the strongest relationships with majority of borderline personality traits, researchers or clinicians should emphasize these two skills during the course of treatment for favorable treatment outcome.

Despite the issue of generalizability, there are also apparent strengths in using a nonclinical sample. Examining borderline personality traits in the general population could provide information regarding the conditions for susceptibility and the prevalence of the disorder and its symptoms in nonclinical populations. Moreover, since past research has found that people with borderline personality features have difficulties similar to those found in BPD patients (Trull, 1995), understanding BPD symptomatology in the general population could allow us to implement detection and early intervention programs for at-risk individuals, which could prevent the symptoms from progressing to a degree of clinical severity.

Overall, by understanding the interplay between mindfulness and various psychological symptoms and outcomes, researchers and clinicians may be able to advance treatments to promote greater psychological functioning and overall well-being.

\section{References}

Baer, R. A. (2011). Measuring Mindfulness. Contemporary Buddhism: An Interdisciplinary Journal, 12, $241-261$. http://dx.doi.org/10.1080/14639947.2011.564842

Baer, R. A., Smith, G. T., \& Allen, K. R. (2004). Assessment of Mindfulness by Self-Report: The Kentucky Inventory of Mindfulness Skills. Assessment, 11, 191-206. http://dx.doi.org/10.1177/1073191104268029

Baer, R. A., Smith, G. T., Hopkins, J., Krietemeyer, J., \& Toney, L. (2006). Using Self-Report Assessment Methods to Explore Facets of Mindfulness. Assessment, 13, 27-45. http://dx.doi.org/10.1177/1073191105283504

Baer, R. A., Smith, G., Lykins, E. L. B., Button, D., Krietemeyer, J., Sauer, S., et al. (2008). Construct Validity of the Five Facet of Mindfulness Questionnaire in Meditating and Non-Meditating Samples. Assessment, 15, 329-342. http://dx.doi.org/10.1177/1073191107313003

Barnhofer, T., Duggan, D. S., \& Griffith, J. W. (2011). Dispositional Mindfulness Moderates the Relation between Neuroticism and Depressive Symptoms. Personality and Individual Differences, 51, 958-962. http://dx.doi.org/10.1016/j.paid.2011.07.032

Bijttebier, P., \& Vertommen, H. (1999). Coping Strategies in Relation to Personality Disorders. Personality and IndividualDifferences, 26, 847-856. http://dx.doi.org/10.1016/S0191-8869(98)00187-1

Bishop, S. R., Lau, M., Shapiro, S., Carlson, L., Anderson, N. D., Carmody, J., \& Devins, G. (2004). Mindfulness: A Proposed Operational Definition. Clinical Psychology: Science and Practice, 11, 230-241. http://dx.doi.org/10.1093/clipsy.bph077 
Bornovalova, M., Lejuez, C., Daughters, S., Rosenthal, Z. M., \& Lynch, T. (2005). Impulsivity as a Common Process across Borderline Personality and Substance Use Disorders. Clinical Psychology Review, 25, Article ID: 790812. http://dx.doi.org/10.1016/j.cpr.2005.05.005

Brown, K. W., \& Ryan, R. M. (2003). The Benefits of Being Present: Mindfulness and Its Role in Psychological Well-Being. Journal of Personality and Social Psychology, 84, 822-848. http://dx.doi.org/10.1037/0022-3514.84.4.822

Brown, K. W., Ryan, R. M., \& Creswell, J. (2007). Mindfulness: Theoretical Foundations and Evidence for Its Salutary Effects. Psychological Inquiry, 18, 211-237. http://dx.doi.org/10.1080/10478400701598298

Carlson, L. E., \& Garland, S. N. (2005). Impact of Mindfulness-Based Stress Reduction (MBSR) on Sleep, Mood, Stress and Fatigue Symptoms in Cancer Outpatients. International Journal of Behavioral Medicine, 12, 278-285. http://dx.doi.org/10.1207/s15327558ijbm1204_9

Carlson, L. E., Speca, M., Patel, K. D., \& Goodey, E. (2003). Mindfulness-Based Stress Reduction in Relation to Quality of Life, Mood, Symptoms of Stress, and Immune Parameters in Breast and Prostate Cancer Outpatients. Psychosomatic Medicine, 65, 571-581. http://dx.doi.org/10.1097/01.PSY.0000074003.35911.41

Carmody, J., \& Baer, R. A. (2008). Relationships between Mindfulness Practice and Levels of Mindfulness, Medical and Psychological Symptoms and Well-Being in a Mindfulness-Based Stress Reduction Program. Journal of Behavioral Medicine, 31, 23-33. http://dx.doi.org/10.1007/s10865-007-9130-7

Chambers, R., Lo, B. C. Y., \& Allen, N. B. (2008). The Impact of Intensive Mindfulness Training on Attentional Control, Cognitive Style, and Affect. Cognitive Therapy and Research, 32, 303-322. http://dx.doi.org/10.1007/s10608-007-9119-0

Chanen, A. M., Jovev, M., Djaja, D., McDougall, E., Yuen, H. P., Rawlings, D., \& Jackson, H. J. (2008). Screening for Borderline Personality Disorder in Outpatient Youth. Journal of Personality Disorders, 22, 353-364. http://dx.doi.org/10.1521/pedi.2008.22.4.353

Claridge, G., \& Broks, P. (1984). Schizotypy and Hemisphere Function: I. Theoretical Considerations and the Measurement of Schizotypy. Personality and Individual Differences, 5, 633-648. http://dx.doi.org/10.1016/0191-8869(84)90111-9

Dimeff, L. A., \& Koerner, K. (2007). Dialectical Behavior Therapy in Clinical Practice. New York: Guilford Press.

Evans, S., Ferrando, S., Findler, M., Stowell, C., Smart, C., \& Haglin, D. (2008). Mindfulness-Based Cognitive Therapy for Generalized Anxiety Disorder. Journal of Anxiety Disorders, 22, 716-721. http://dx.doi.org/10.1016/j.janxdis.2007.07.005

Falkenström, F. (2010). Studying Mindfulness in Experienced Meditators: A Quasi-Experimental Approach. Personality and Individual Differences, 48, 305-310. http://dx.doi.org/10.1016/j.paid.2009.10.022

Fonseca-Pedrero, E., Paino, M., Lemos-Giraldez, S., Sierra-Baigrie, S., Garcia-Portilla Gonzalez, M. P., \& Bobes, J. (2011). Borderline Personality Traits in Nonclinical Young Adults. Journal of Personality Disorders, 25, 542-556. http://dx.doi.org/10.1521/pedi.2011.25.4.542

Goldin, P. R., \& Gross, J. J. (2010). Effects of Mindfulness-Based Stress Reduction (MBSR) on Emotion Regulation in Social Anxiety Disorder. Emotion, 10, 83-91. http://dx.doi.org/10.1037/a0018441

Gratz, K. L., Breetz, A., \& Tull, M. T. (2010). The Moderating Role of Borderline Personality in the Relationships between Deliberate Self-Harm and Emotion-Related Factors. Personality and Mental Health, 4, 96-10.

Grossman, P., Niemann, L., Schmidt, S., \& Walach, H. (2004). Mindfulness-Based Stress Reduction and Health Benefits: A Meta-Analysis. Journal of Psychosomatic Research, 57, 35-43. http://dx.doi.org/10.1016/S0022-3999(03)00573-7

Gunderson, J. G., \& Zanarini, M. C. (1987). Current Overview of the Borderline Diagnosis. Journal of Clinical Psychiatry, 48, 5-11.

Hayes, A. M., Beevers, C. G., Feldman, G. C., Laurenceau, J. P., \& Perlman, C. (2005). Avoidance and Processing as Predictors of Symptom Change and Positive Growth in an Integrative Therapy for Depression. International Journal of Behavioral Medicine, 12, 111-122. http://dx.doi.org/10.1207/s15327558ijbm1202_9

Hayes, S. C., Strosahl, K. D., \& Wilson, K. G. (1999). Acceptance and Commitment Therapy an Experiential Approach to Behavior Change. New York: The Guilford Press.

Hayes, S. C., Wilson, K. G., Gifford, E. V., Follette, V. M., \& Strosahl, K. (1996). Experiential Avoidance and Behavioral Disorders: A Functional Dimensional Approach to Diagnosis and Treatment. Journal of Consulting and Clinical Psychology, 64, 1152-1168. http://dx.doi.org/10.1037/0022-006X.64.6.1152

Hill, C. L. M., \& Updegraff, J. A. (2012). Mindfulness and Its Relationship to Emotional Regulation. Emotion, 12, 81-90. http://dx.doi.org/10.1037/a0026355

Hofmann, S. G., Sawyer, A. T., Witt, A. A., \& Oh, D. (2010). The Effect of Mindfulness-Based Therapy on Anxiety and Depression: A Meta-Analytic Review. Journal of Consulting and Clinical Psychology, 78, 169-183. http://dx.doi.org/10.1037/a0018555

International Wellbeing Group (2006). Personal Wellbeing Index (Manual). Melbourne: Deakin University, Australian Centre on Quality of Life. 
Jain, S., Shapiro, S. L., Swanick, S., Roesch, S. C., Mills, P. J., Bell, I., \& Schwartz, G. E. R. (2007). A Randomized Controlled Trial of Mindfulness Meditation versus Relaxation Training: Effects on Distress, Positive States of Mind, Rumination, and Distraction. Annals of Behavioral Medicine, 33, 11-21. http://dx.doi.org/10.1207/s15324796abm3301_2

Kabat-Zinn, J. (1982). An Outpatient Program in Behavioral Medicine for Chronic Pain Patients Based on the Practice of Mindfulness Meditation: Theoretical Considerations and Preliminary Results. General Hospital Psychiatry, 4, 33-47. http://dx.doi.org/10.1016/0163-8343(82)90026-3

Kabat-Zinn, J. (1994). Wherever You Go, There You Are: Mindfulness Meditation in Everyday Life. New York: Hyperion.

Kang, C., \& Whittingham, K. (2010). Mindfulness: A Dialogue between Buddhism and Clinical Psychology. Mindfulness, 1, 161-173. http://dx.doi.org/10.1007/s12671-010-0018-1

Keng, S. L., Smoski, M. J., \& Robins, C. J. (2011). Effects of Mindfulness on Psychological Health: A Review of Empirical Studies. Clinical Psychology Review, 31, 1041-1056. http://dx.doi.org/10.1016/j.cpr.2011.04.006

Kim, B., Lee, S. H., Kim, Y. W., Choi, T. K., Yook, K., Suh, S. Y., Cho, S. J. \& Yook, K.-H. (2010). Effectiveness of a Mindfulness-Based Cognitive Therapy Program as an Adjunct to Pharmacotherapy in Patients with Panic Disorder. Journal of Anxiety Disorders, 24, 590-595. http://dx.doi.org/10.1016/j.janxdis.2010.03.019

King, A. P., Erickson, T. M., Giardino, N. D., Favorite, T., Rauch, S. A. M., Robinson, E., Kulkarni, M., \& Liberzon, I. (2013). A Pilot Study of Group Mindfulness-Based Cognitive Therapy (MBCT) for Combat Veterans with Posttraumatic Stress Disorder (PTSD). Depression and Anxiety, 30, 638-645. http://dx.doi.org/10.1002/da.22104

Kline, R. (1998). Principles and Practice of Structural Equation Modeling. New York: The Guilford Press.

Koenigsberg, H., Harvey, P., Mitropoulou, V., Schmeidler, J., New, A., Goodman, M., Silverman, J., Serby, M., Schopick, F. \& Siever, L. (2002). Characterizing Affective Instability in Borderline Personality Disorder. The American Journal of Psychiatry, 159, 784-788. http://dx.doi.org/10.1176/appi.ajp.159.5.784

Kruedelbach, N., McCormick, R. A., Schulz, S. C., \& Grueneich, R. (1993). Impulsivity, Coping Styles, and Triggers for Cravings in Substance Abusers with Borderline Personality Disorder. Journal of Personality Disorders, 7, $214-222$. http://dx.doi.org/10.1521/pedi.1993.7.3.214

Lau, M. A., Bishop, S. R., Segal, Z. V., Buis, T., Anderson, N. D., Carlson, L., Shapiro, S., Carmody, J., Abbey, S., \& Devins, G. (2006). The Toronto Mindfulness Scale: Development and Validation. Journal of Clinical Psychology, 62, 1445-1467. http://dx.doi.org/10.1002/jclp.20326

Leible, T. L., \& Snell Jr., W. E. (2004). Borderline Personality Disorder and Multiple Aspects of Emotional Intelligence. Personality and Individual Differences, 37, 393-404. http://dx.doi.org/10.1016/j.paid.2003.09.011

Linehan, M. M. (1987). Dialectical Behavior Therapy for Borderline Personality Disorder: Theory and Method. Bulletin of the Menninger Clinic, 51, 261-276.

Linehan, M. M., Amstrong, H. E., Suarez, A., Allmon, D. J., \& Heard, H. L. (1991). Cognitive-Behavioral Treatment of Chronically Suicidal Borderline Patients. Archives of General Psychiatry, 48, 1060-1064. http://dx.doi.org/10.1001/archpsyc.1991.01810360024003

Lynch, T. R., Morse, J. Q., Mendelson, T., \& Robins, C. J. (2003). Dialectical Behavior Therapy for Depressed Older Adults. The American Journal of Geriatric Psychiatry, 11, 33-45. http://dx.doi.org/10.1097/00019442-200301000-00006

Morey, L. C. (1991). Personality Assessment Inventory: Professional manual. Odessa, FL: Psychological Assessment Resources.

Nicastro, R., Jermann, F., Bondolfi, G., \& McQuillan, A. (2010). Assessment of Mindfulness with French Version of the Kentucky Inventory of Mindfulness Skills in Community and Borderline Personality Disorder Samples. Assessment, 17, 197-205. http://dx.doi.org/10.1177/1073191110363551

Nyklíček, I., \& Kuijpers, K. F. (2008). Effects of Mindfulness-Based Stress Reduction Intervention on Psychological Well-Being and Quality of Life: Is Increased Mindfulness Indeed the Mechanism? Annals of Behavioral Medicine, 35, 331-340. http://dx.doi.org/10.1007/s12160-008-9030-2

O’Toole, S. K., Diddy, E., \& Kent, M. (2011). Mindfulness and Emotional Well-Being in Women with Borderline Personality Disorder. Mindfulness, 3, 117-123. http://dx.doi.org/10.1007/s12671-011-0085-y

Patton, J. H., Stanford, M. S., \& Barratt, E. S. (1994). Factor Structure of the Barratt Impulsiveness Scale. Journal of Clinical Psychology, 51, 768-774. http://dx.doi.org/10.1002/1097-4679(199511)51:6<768::AID-JCLP2270510607>3.0.CO;2-1

Perroud, N., Nicastro, R., Jermann, F., \& Huguelet, P. (2012). Mindfulness Skills in Borderline Personality Disorder Patients during Dialectical Behavior Therapy: Preliminary Results. International Journal of Psychiatry in Clinical Practice, 16, 189-196. http://dx.doi.org/10.3109/13651501.2012.674531

Peters, J. R., Erisman, S. M., Upton, B. T., Baer, R. A., \& Roemer, L. (2011). A Preliminary Investigation of the Relationships between Dispositional Mindfulness and Impulsivity. Mindfulness, 2, 228-235. http://dx.doi.org/10.1007/s12671-011-0065-2

Peters, J. R., Upton, B. T., \& Baer, R. A. (2013). Brief Report: Relationships between Facets of Impulsivity and Borderline 
Personality Features. Journal of Personality Disorders, 27, 547-552. http://dx.doi.org/10.1521/pedi_2012_26_044

Piet, J., Würtzen, H., \& Zachariae, R. (2012). The Effect of Mindfulness-Based Therapy on Symptoms of Anxiety and Depression in Adult Cancer Patients and Survivors: A Systematic Review and Meta-Analysis. Journal of Consulting and Clinical Psychology, 80, 1007-1020. http://dx.doi.org/10.1037/a0028329

Poreh, A. M., Rawlings, D., Claridge, G., Freeman, J. L., Faulkner, C., \& Shelton, C. (2006). The BPQ: A Scale for the Assessment of Borderline Personality Based on DSM-IV Criteria. Journal of Personality Disorders, 20, 247-260. http://dx.doi.org/10.1521/pedi.2006.20.3.247

Rosenthal, M. Z., Cheavens, J. S., Lejuez, C. W., \& Lynch, T. R. (2005). Thought Suppression Mediates the Relationship between Negative Affect and Borderline Personality Disorder Symptoms. Behaviour Research and Therapy, 43, 11731185. http://dx.doi.org/10.1016/j.brat.2004.08.006

Roth, B., \& Robbins, D. (2004). Mindfulness-Based Stress Reduction in Health-Related Quality of Life: Findings from a Bilingual Inner-City Patient Population. Psychosomatic Medicine, 66, 113-123. http://dx.doi.org/10.1097/01.PSY.0000097337.00754.09

Rüsch, N., Lieb, K., Göttler, I., Hermann, C., Schramm, E., Richter, H., Jacob, G. A., Corrigan, P. W., \& Bohus, M. (2007). Shame and Implicit Self-Concept in Women with Borderline Personality Disorder. The American Journal of Psychiatry, 164, 500-508.

Safer, D. L., Telch, C. F., \& Agras, W. S. (2001). Dialectical Behavior Therapy for Bulimia Nervosa. The American Journal of Psychiatry, 158, 632-634. http://dx.doi.org/10.1176/appi.ajp.158.4.632

Schutte, N. S., \& Malouff, J. M. (2011). Emotional Intelligence Mediates the Relationship between Mindfulness and Subjective Well-Being. Personality and Individual Differences, 50, 1116-1119. http://dx.doi.org/10.1016/j.paid.2011.01.037

Segal, Z. V., Williams, J. M. G., \& Teasdale, J. D. (2002). Mindfulness-Based Cognitive Therapy for Depression: A New Approach to Preventing Relapse. New York: Guildford Press.

Shapiro, S. L., Brown, K. W., \& Biegal, G. M. (2007). Teaching Self-Care to Caregivers: Effects of Mindfulness-Based Stress Reduction on the Mental Health of Therapists in Training. Training and Education in Professional Psychology, 1, 105-115. http://dx.doi.org/10.1037/1931-3918.1.2.105

Shapiro, S. L., Schwartz, G. E., \& Bonner, G. (1998). Effects of Mindfulness-Based Stress Reduction on Medical and Premedical Students. Journal of Behavioral Medicine, 21, 581-599. http://dx.doi.org/10.1023/A:1018700829825

Speca, M., Carlson L.E., Goodey, E., \& Angen, M. (2000). A Randomized, Wait-List Controlled Clinical Trial: The Effect of a Mindfulness Meditation-Based Stress Reduction Program on Mood and Symptoms of Stress in Cancer Outpatients. Psychosomatic Medicine, 62, 613-622. http://dx.doi.org/10.1097/00006842-200009000-00004

Stepp, S. D., Epler, A. J., Jahng, S., \& Trull, T. J. (2008). The Effect of Dialectical Behavior Therapy Skills Use on Borderline Personality Disorder Features. Journal of Personality Disorders, 22, 549-563. http://dx.doi.org/10.1521/pedi.2008.22.6.549

Stone, M. H. (1990). The Fate of Borderline Patients: Successful Outcome and Psychiatric Practice. New York: Guilford Press.

Tabachnick, B. G., \& Fidell, L. S. (2001). Using Multivariate Statistics (4th ed.). Boston, MA: Allyn \& Bacon.

Teasdale, J. D., Segal, Z. V., \& Williams, J. M. G. (1995). How Does Cognitive Therapy Prevent Depressive Relapse and Why Should Attentional Control (Mindfulness) Training Help? Behaviour Research and Therapy, 33, 25-39. http://dx.doi.org/10.1016/0005-7967(94)E0011-7

Teasdale, J. D., Segal, Z. V., Williams, J. M. G., Ridgeway, V. A., Soulsby, J. M., \& Lau, M. A. (2000). Prevention of Relapse/Recurrence in Major Depression by Mindfulness-Based Cognitive Therapy. Journal of Consulting and Clinical Psychology, 68, 615-623. http://dx.doi.org/10.1037/0022-006X.68.4.615

Trull, T. (1995). Borderline Personality Disorder Features in Nonclinical Young Adults: 1. Identification and Validation. Psychological Assessment, 7, 33-41. http://dx.doi.org/10.1037/1040-3590.7.1.33

Walach, H., Buchheld, N., Buttenmüller, V., Kleinknecht, N., \& Schmidt, S. (2006). Measuring Mindfulness-The Freiburg Mindfulness Inventory (FMI). Personality and Individual Differences, 40, 1543-1555. http://dx.doi.org/10.1016/j.paid.2005.11.025

Weinstein, N., Brown, K. W., \& Ryan, R. M. (2009). A Multi-Method Examination of the Effects of Mindfulness on Stress Attribution, Coping, and Emotional Well-Being. Journal of Research in Personality, 43, 374-385.

http://dx.doi.org/10.1016/j.jrp.2008.12.008

Widiger, T. (1992). Categorical versus Dimensional Classification: Implications from and for Research. Journal of Personality Disorders, 6, 287-300. http://dx.doi.org/10.1521/pedi.1992.6.4.287

Widiger, T. A., \& Trull, T. J. (2007). Plate Tectonics in the Classification of Personality Disorder: Shifting to a Dimensional Model. American Psychologist, 62, 71-83. http://dx.doi.org/10.1037/0003-066X.62.2.71

Williams, J. M. G., Alatiq, Y., Crane. C., Barnhofer, T., Fennell, M. J. V., Duggan, D. S., Hepburn, S., \& Goodwin, G.M. 
(2008). Mindfulness-Based Cognitive Therapy (MBCT) in Bipolar Disorder: Preliminary Evaluation of Immediate Effects on Between-Episode Functioning. Journal of Affective Disorders, 103, 275-279. http://dx.doi.org/10.1016/j.jad.2007.08.022

Wupperman, P., Neumann, C. S., \& Axelrod, S. R. (2008). Do Deficits in Mindfulness Underline Borderline Personality Features and Core Difficulties? Journal of Personality Disorders, 22, 466-482. http://dx.doi.org/10.1521/pedi.2008.22.5.466

Zanarini, M. C., Frankenburg, F. R., Dubo, E. D., Sickel, A. E., Trikha, A., Levin, A., \& Reynolds, V. (1998). Axis I Comorbidity of Borderline Personality Disorder. The American Journal of Psychiatry, 155, 1733-1739. http://dx.doi.org/10.1176/ajp.155.12.1733

Zanarini, M. C., Vujanovic, A. A., Parachini, E. A., Boulanger, J. L., Frankenburg, F. R., \& Hennen, J. (2003). A Screening Measure for BPD: The McLean Screening Instrument for Borderline Personality Disorder (MSI-BPD). Journal of Personality Disorders, 17, 568-573. http://dx.doi.org/10.1521/pedi.17.6.568.25355 